UCRL-JC-129728

Preprint

\title{
The Effects of Pressure, Temperature and Concentration on the Reactivity of Alkanes: Experiments and Modeling in a Rapid Compression Machine
}

\author{
C. K. Westbrook, H. J. Curran, and W. J. Pitz
}

J. F. Griffiths, C. Mohamed, and S. K. Wo

This paper was prepared for submittal to

27th International Symposium on Combustion, University of Colorado at Boulder,

September 2-7, 1998

January 8, 1998

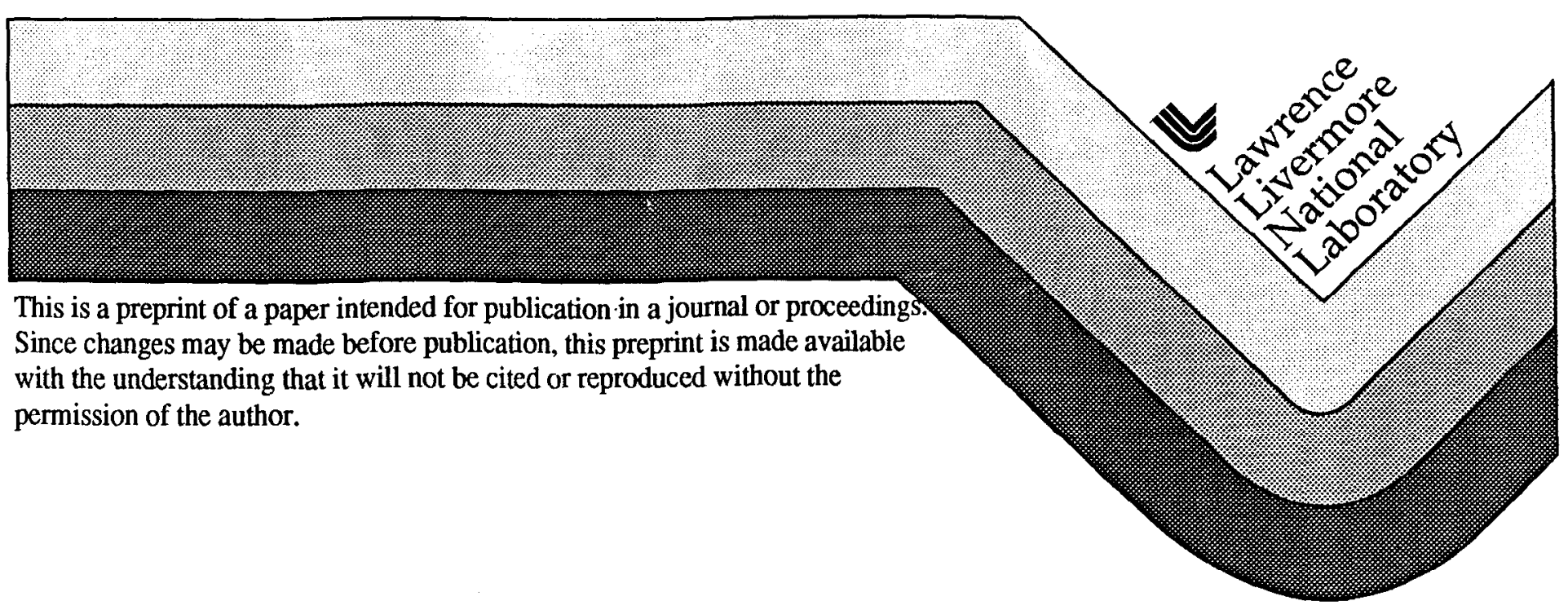




\section{DISCLAIMER}

This document was prepared as an account of work sponsored by an agency of the United States Govermment. Neither the United States Government nor the University of Califomia nor any of their employees, makes any warranty, express or implied, or assumes any legal liability or responsibility for the accuracy, completeness, or usefulness of any information, apparatus, product, or process disclosed, or represents that its use would not infringe privately owned rights. Reference herein to any specific commercial product, process, or service by trade name, trademark, manufacturer, or otherwise, does not necessarily constitute or imply its endorsement, recommendation, or favoring by the United States Government or the University of California. The views and opinions of authors expressed herein do not necessarily state or reflect those of the United States Govemment or the University of California, and shall not be used for advertising or product endorsement purposes. 


\title{
The Effects of Pressure, Temperature and Concentration on the Reactivity of Alkanes: Experiments and Modeling in a Rapid Compression Machine
}

\author{
C. K. Westbrook, H. J. Curran, and W. J. Pitz \\ Lawrence Livermore National Laboratory, Livermore, CA 94551 USA \\ and \\ J. F. Griffiths, C. Mohamed, and S. K. Wo \\ Leeds University, Leeds LS2 9JT United Kingdom
}

\begin{abstract}
Experiments in a rapid compression machine have examined the influences of variations in pressure, temperature, and equivalence ratio on the autoignition of $n$-pentane. Equivalence ratios included values from 0.5 to 2.0, compressed gas initial temperatures were varied between $675 \mathrm{~K}$ and $980 \mathrm{~K}$, and compresed gas initial pressures varied from 8 to 20 bar. Numerical simulations of the same experiments were carried out using a detailed chemical kinetic reaction mechanism. The results are interpreted in terms of a low temperature oxidation mechanism involving addition of molecular oxygen to alkyl and hydroperoxyalkyl radicals. Idealized calculations are reported which identify the major reaction paths at each temperature. Results indicate that in most cases, the reactive gases experience a two-stage autoignition. The first stage follows a low temperature alkylperoxy radical isomerization pathway that is effectively quenched when the temperature reaches a level where dissociation reactions of alkylperoxy and hydroperoxyalkylperoxy radicals are more rapid than the reverse addition steps. The second stage is controlled by the onset of dissociation of hydrogen peroxide. Results also show that in some cases, the first stage ignition takes place during the compression stroke in the rapid compression machine, making the interpretation of the experiments somewhat more complex than generally assumed. At the highest compression temperatures achieved, little or no first stage ignition is observed.
\end{abstract}




\section{Introduction}

The problem of hydrocarbon ignition is central to a wide range of practical combustion systems, including internal combustion engines, detonations, pulse combustors, and flame initiation. The rapid compression machine (RCM) has long been used to study the kinetics of hydrocarbon autoignition [e.g., 1-7], since the reactive gas temperatures and time histories are similar to those encountered in automotive engines during Diesel ignition and end gas autoignition which leads to engine knock in sparkignition engines.

The RCM provides a rich environment from which data may be drawn to study the theory of hydrocarbon oxidation, including degenerate chain branching, alkylperoxy radical isomerization and effects of thermal feedback [8]. The literature of hydrocarbon oxidation studies in the RCM has been summarized recently $[9,10]$, and many classes of fuels have been studied. Detailed kinetic modeling has also been added to the diagnostic tools available to study hydrocarbon oxidation in the RCM [4]. Although pressure dependences have been investigated previously [5-7], the present study in an $\mathrm{RCM}$ is unusual in that effects of variations in fuel/oxygen equivalence ratio, initial pressure and compressed gas temperature have been studied simultaneously for a single hydrocarbon fuel, n-pentane. The aim of this work is to determine experimentally the influence of variations in equivalence ratio, temperature, and pressure on autoignition, and to use a kinetic model to understand the reasons for those variations. 


\section{Experimental}

The rapid compression machine consists of a stainless steel piston, fitted with ptfe seals, which is driven by compressed air into a cylindrical chamber. The compression stroke is $20 \mathrm{~cm}$, the piston speed is about $10 \mathrm{~m} / \mathrm{s}$, and the compression ratio is $11.2 \pm 0.2$. Once piston motion stops, combustion takes place in a closed constant volume. The walls of the cylinder and combustion chamber are maintained at constant temperature in the range $313-348 \mathrm{~K}$. The compression stroke is sufficiently fast ( $\sim 22 \pm 1 \mathrm{~ms})$ for it to be a virtually adiabatic process. Full details of the machine and its operation are given elsewhere [1,11-14].

Pressure is measured during compression and the postcompression period using a Kistler transducer and recorded digitally at a sampling rate of $200 \mu$ s per point via an A/D converter. The cylinder head consists of a quartz window giving a full field of view of the chamber (diameter $4.5 \mathrm{~cm}$ ), through which chemiluminescent emissions are detected by photomultiplier and recorded simultaneously with the pressure records.

There is no mechanism to lock the piston at the end of its travel, so the piston is held in its final position by the pressure in the compressed air tank. Past safe operating conditions had imposed a limit to the gas pressure at the end of compression of about 12 bar. To perform higher pressure experiments, the air receiver of the tank has been upgraded for this study, and experiments performed at compressed gas pressures of up to 22 bar are reported here. 
We define ignition delay as the time from the end of the compression stroke to the time of maximum rate of pressure rise. However, as discussed elsewhere $[1,4]$, reaction may begin before the piston has stopped. Consequently, the gas temperature and pressure reached at the end of compression may exceed that which would result solely from an adiabatic compression. In these circumstances, the variation of ignition delay is taken to be the adiabatic temperature, $T_{a d}$, obtained from the ideal relationship

$$
\mathrm{T}_{\mathrm{ad}}=\mathrm{T}_{\mathrm{o}}(\mathrm{CR})^{\gamma-1}
$$

where $\gamma$ is the ratio of the conventional temperature-dependent heat capacities. Where there is negligible reaction during compression, the value of $T_{a d}$ does not differ significantly from the compressed gas temperature $T_{C}$ derived from the relationship

$$
T_{C}=T_{o}\left(P_{C} / P_{o}\right)^{\gamma-1}
$$

which confirms that the compression is almost adiabatic. The subscripts o and $\mathrm{c}$ represent initial and final compression conditions.

Compressed gas temperature was varied in the experiments by changing the proportions of the inert diluents $\left(\mathrm{CO}_{2} / \mathrm{N}_{2} / \mathrm{Ar}\right)$ representing the non-reactive components of the air mixture, as described previously $[1,4]$. Changes in the inert composition alter the $\gamma$ of the reactants and therefore the temperature increase on compression. Reactant mixtures covered 
compositions of $n$-pentane at equivalence ratins of $\phi=0.5,0.6,0.75,1.0,1.25$, 1.5 and 2.0. Initial pressures were 0.33 bar, yielding adiabatic compressed gas pressures in the range $8-10$ bar. In addition, the behavior of n-pentane mixtures at $\phi=1$ was studied at initial pressures of 0.5 and 0.67 bar, yielding adiabatic compressed gas pressures of $12-14$ and $17-19$ bar respectively. Appreciably higher compressed gas pressures were reached when there was significant reaction and accompanying heat release during compression.

\section{Kinetic Model}

Numerical modeling calculations were carried out using the HCT program [15], which solves the coupled nonlinear differential equations for conservation of mass, momentum, energy and each chemical species in finite-difference form. The moving piston was represented by a moving cell boundary of the computational volume, achieving the same compression history as in the experiments. Heat losses to combustion chamber walls were included by comparing experimental and computed pressure records for nonreactive mixtures in which the fuel was replaced with nitrogen to calibrate an overall heat transfer coefficient. Thus the model does not include spatial variations in temperature and species concentrations; previous studies using multidimensional models have shown [16-18] that some features of ignition in the present apparatus require treatment of spatial variations, but the present purely kinetic simulations can address the great majority of the phenomena of interest in this study. 
The kinetic reaction mechanism for n-pentane oxidation used here has been developed as part of a systematic effort to model hydrocarbon oxidation over wide temperature ranges. Recent studies used the same approach to describe oxidation of neopentane [19], n-heptane [20], isomers of hexane [21] and automotive primary reference fuels $[22,23]$. The methodology for determining elementary reaction rate parameters is described in considerable detail in Reference [20]. The present mechanism for $\mathrm{n}$-pentane oxidation includes 450 chemical species and 2100 elementary chemical reactions. The reaction mechanism distinguishes between different sites in the reactant molecule and follows oxidation through addition of molecular oxygen to alkyl radicals, isomerization to produce hydroperoxyalkyl radicals, further addition of molecular oxygen to produce ketohydroperoxides, and decomposition to produce radicals and stable intermediate species. The major chain branching reaction paths depend very strongly on the equilibrium constants of the $\mathrm{O}_{2}$ addition reactions to alkyl and hydroperoxyalkyl radicals and are therefore very sensitive to changes in temperature $[24,25]$.

\section{Isothermal Modeling Calculations}

Idealized modeling calculations were also performed to identify key reaction paths and quantify overall rates of n-pentane oxidation under conditions like those in the RCM. In these calculations isothermal conditions were simulated at selected temperatures over a range $700 \mathrm{~K} \leq \mathrm{T} \leq 1000 \mathrm{~K}$ and at pressures typical of those found at the completion of the compression stroke. 
Isothermal reaction was maintained by enhancing the heat transfer coefficient to suppress thermal feedback that would cause self-heating and ignition. Consequently, a distinct path for fuel oxidation was identified depending uniquely on the mixture composition, pressure and temperature. For each simulation, there is a period where the fuel consumption rate is nearly constant over more than $50 \%$ consumption of the fuel. Fuel consumption rate is a characteristic of the reaction mechanism under those conditions and the reaction paths found to control the rate of fuel consumption provide valuable insight into details of fuel oxidation in the RCM.

Figure 1 shows computed quasisteady rates of fuel consumption at pressures of 8 and 16 bar for stoichiometric mixtures of n-pentane and oxygen, with an equimolar diluent of nitrogen and argon. These pressures are similar to the post-compression pressures in this RCM when the initial precompression pressures are 0.33 and 0.67 bar, respectively. Rates of fuel

consumption are expressed in units of change of mole fraction per second. At 8 bar, the maximum rate of $n$-pentane oxidation occurs at $760 \mathrm{~K}$ and the minimum rate at $910 \mathrm{~K}$. At 16 bar these values shift to temperatures approximately $50 \mathrm{~K}$ higher. Magnitudes of the overall rates also increase significantly with increasing pressure.

\section{Reaction Paths}

From these idealized isothermal calculations, important reaction paths become clear. Below $750-800 \mathrm{~K}$, the overall rate of reaction is controlled by 
the rate of chain branching through production and decomposition of ketohydroperoxide species. This path begins with abstraction by a radical species $\mathrm{X}$ (usually $\mathrm{OH}$ or $\mathrm{HO}_{2}$ ) of an $\mathrm{H}$ atom from the fuel $\mathrm{RH}$ and proceeding:

(1) $\mathrm{RH}+\mathrm{X}=\mathrm{HX}+\mathrm{R}$

(2) $\mathrm{R}+\mathrm{O}_{2}=\mathrm{RO}_{2}$

(3) $\mathrm{RO}_{2}=\mathrm{QOOH}$

(4) $\mathrm{QOOH}+\mathrm{O}_{2}=\mathrm{O}_{2} \mathrm{QOOH}$
$\mathrm{H}$ atom abstraction from fuel

Addition of molecular oxygen to alkyl

Isomerization to form hydroperoxyalkyl

Addition of additional molecular $\mathrm{O}_{2}$

Decomposition to $\mathrm{OH}+$ ketohydroperoxide

Decomposition to $\mathrm{OH}+$ carbonyl radical

Consumption of one radical $X$, in steps of the type (1) - (6) produces three radicals $(2 \mathrm{OH}+\mathrm{KO})$, resulting in a high rate of chain branching $[4,20,23]$. However, a requirement is that rates of addition of $\mathrm{O}_{2}$ to alkyl (2) and hydroperoxyalkyl (4) radicals exceed rates of the reverse decomposition reactions. Activation energies for these decomposition reactions are not less than $30 \mathrm{kcal} / \mathrm{mol}$, so the chain branching route is suppressed only at higher temperatures when the rate of decomposition is sufficiently fast to shut off this path. Equilibrium constants for reactions (2) and (4) are strongly dependent on temperature, but since there is also a change in the number of moles in each addition reaction, a pressure increase shifts the reaction in the direction of the adduct species. Based on the present computations, an 
increase in pressure of a factor of two increases the temperatures at which the decompositions begin to control the reaction by about 50K, as seen in Fig. 1 .

As the reaction temperature is further increased above about $900 \mathrm{~K}$, the decomposition rate of the $\mathrm{R}+\mathrm{O}_{2}$ reaction increases rapidly, reducing the chain branching rate and lowering the overall rate of reaction. Over this range of temperatures, there are many reactions which produce $\mathrm{HO}_{2}$ radicals, including reactions of $\mathrm{O}_{2}$ with radicals such as $\mathrm{HCO}, \mathrm{CH}_{2} \mathrm{CHO}$, and $\mathrm{CH}_{3} \mathrm{O}$, as well as decomposition of some classes of $\mathrm{QOOH}$ radicals [20]. These radicals then react via two major classes of reactions to produce $\mathrm{H}_{2} \mathrm{O}_{2}$ :

$$
\begin{aligned}
& \mathrm{HO}_{2}+\mathrm{HO}_{2}=\mathrm{H}_{2} \mathrm{O}_{2}+\mathrm{O}_{2} \\
& \mathrm{RH}+\mathrm{HO}_{2}=\mathrm{R}+\mathrm{H}_{2} \mathrm{O}_{2} .
\end{aligned}
$$

and

The activation energy for $\mathrm{H}_{2} \mathrm{O}_{2}$ decomposition is large enough $(\sim 45 \mathrm{kcal} / \mathrm{mol})$ that its decomposition is still quite slow in this temperature range. As temperature increases, the rate of decomposition accelerates until hydrogen peroxide decomposition begins to provide chain branching, producing two $\mathrm{OH}$ radicals for each $\mathrm{H}_{2} \mathrm{O}_{2}$ species consumed. At temperatures where overall reaction rates are lowest in Fig. 1 (i.e., $910 \mathrm{~K}$ for 8 bar, $960 \mathrm{~K}$ for 16 bar), the rate of $\mathrm{H}_{2} \mathrm{O}_{2}$ decomposition is still negligible and the rate of chain branching via the low temperature $\mathrm{RO}_{2}$ mechanism is also very small. 
These concepts of minimum and maximum rate of reaction and the kinetic pathways responsible are important in the interpretations below of the RCM ignition results. The actual reaction paths followed in the RCM can be quite complicated, making analysis difficult in some cases, so it is useful to have these reference calculations to assist in interpretation of the results.

\section{Results}

The experimentally observed effect of equivalence ratio at initial pressures of 0.33 bar on ignition of n-pentane following compression to $765 \mathrm{~K}$ is shown in Fig. 2. As $\phi$ is decreased from 1 to 0.5 the total ignition delay (relative to end of compression at $22 \mathrm{~ms}$ ) increases from $6.2 \mathrm{~ms}$ to $40.8 \mathrm{~ms}$. The time delay before the first stage ignition remains essentially constant at about $1-2 \mathrm{~ms}$, but the rate and extent of pressure rise during that first stage decrease considerably. This indicates a reduced rate and extent of heat release and smaller temperature increase during the first stage, results confirmed in the numerical simulations. The time delay before the second stage ignition increases considerably as $\phi$ decreases, due to the lower temperature and extent of reaction following the first stage.

By contrast, following compression to $725 \mathrm{~K}$, the first slage ignition delay decreases as $\phi$ is increased from 1 to 2 (Fig. 3). Between $\phi=1.0$ and 1.5, the first stage extent of pressure rise increases, indicating greater temperature increase and rate of heat release, confirmed in the model calculations.

- Consequently, earlier development of the second stage is observed. 
Variations in overall ignition delay time with equivalence ratio

$(0.5 \leq \phi \leq 2)$ and compressed gas temperature are summarized in Fig. 4.

Experimental results have been fit to smooth curves; symbols represent

model calculations discussed below. At any given $T_{C}$ the ignition delay

decreases as $\phi$ increases; however, measured results over $\phi=1.25-2.0$ were all nearly identical.

Results in Fig. 4 show a non-monotonic behavior typical of the type of negative temperature coefficient (ntc) of reaction characteristic of alkane oxidation in isothermal experiments [e.g., 26]. The location and extent of this ntc region vary with $\phi$ in Fig. 4, with little ntc behavior indicated in the experimental results for the leanest and richest mixtures.

Computed results are shown as symbols in Fig. 4. For most values of $\phi$, computed ignition delay times agree extremely well with observations. Variations with equivalence ratio are accurately reproduced, as is the amount of ntc variation with temperature. However, for the leanest mixtures of $\phi=0.6$ and 0.5, there are significant differences between computed and measured results. For $\phi=0.6$, the computations show a much more exaggerated ntc behavior than is seen in the experimental results. Interestingly, the temperatures where the minimum and maximum ignition delays occur are the same in the measured and computed results. The same trend is observed for the $\phi=0.5$ cases but is even more exaggerated, to the 
point that between $765 \mathrm{~K}$ and $880 \mathrm{~K}$, the computations predict that ignition does not occur. For those mixtures, wall heat losses are sufficient to extinguish ignition in the calculated models, although ignition is observed in the experiments. These differences can be understood by recalling that the model does not include the effects of spatial inhomogeneities in the combustion chamber. In the experiments, heat losses to the chamber walls result in some reactants being at temperatures lower than the core gases. Due to the temperature variability in overall reaction rate as noted in Fig. 1, these colder gases are more reactive and actually cause the mixture to ignite, although the core gases would not otherwise ignite. The same conclusion was reached in a previous study of RCM autoignition with spatial resolution of the combustion volume coupled to a reduced kinetic model [16].

All these results were obtained with an initial precompression pressure of 0.33 bar. The influence of initial pressure was assessed by carrying out measurements for stoichiometric mixtures at initial pressures of 0.50 and 0.67 bar. Results in Fig. 5 show measured pressure histories at compression temperature $T_{C}$ of $835 \mathrm{~K}$ at the three pressures studied. The dashed curves show measured chemiluminescent emission for the three experiments, indicating that the first stage ignition in all three cases occurs very early and, in the highest pressure case, before the end of the compression stroke.

Variations with pressure in overall ignition delay times over the entire temperature range are summarized in Fig. 6. The overall ignition delay decreases sharply with increasing pressure. Al the highest initial pressure of 
0.67 bar, both the experiments and model calculations indicated that for $\mathrm{T}_{\mathrm{ad}} \geq$.

$800 \mathrm{~K}$, the first stage ignition occurred prior to the end of the compression stroke. This makes definition of compressed gas temperature ambiguous, so the results in Fig. 6 are plotted as functions of the adiabatic compression temperature, calculated assuming no reaction during compression.. Both the experiments and model results indicated very short ignition delay times for the higher temperature mixtures at $P_{0}=0.67$ bar. The modeling results predict that the very highest temperature mixtures actually complete both the first and second stage ignition prior to the end of the compression stroke, although only the first stage was observed in the experiments.

\section{Discussion}

Alkane combustion over the range $700-900 \mathrm{~K}$ is unusually complex, as shown above. However, using principles derived from the isothermal modeling calculations, these phenomena can all be interpreted consistently. First Stage Ignition

Provided that negligible reaction takes place during the compression stroke, the reactant gas mixture has an intrinsic reactivity at the end of compression represented by a given state in Fig. 1. There are then a number of possible outcomes, depending on the location of this compressed state. (1) The compressed mixture temperature may be located in a region of low reactivity. For example, at a compressed gas pressure of 8 bar, the reaction rate 
is at its lowest when $T_{C}$ is approximately $900 \mathrm{~K}$ (see Fig. 1) and the RCM ignition delay is at its longest (see Fig. 4, $\phi=1$ ).

(2) $T_{C}$ may be located in a region of very high reactivity. This is represented in Fig. 1 at $760 \mathrm{~K}$ and 8 bar or at $820 \mathrm{~K}$ and 16 bar. For each of these conditions the ignition delay in the RCM is at its minimum.

For mixtures with this high rate of reactivity, rapid heat relcase increases the mixture temperature and pressure until the mixture reaches the region of low reactivity. This then slows the overall rate of reaction significantly and effectively quenches the first stage ignition, as seen in Figs. 2 and 3. In kinetic terms, the rapid rate of reaction continues until the higher temperature increases the rate of $\mathrm{RO}_{2}$ and $\mathrm{O}_{2} \mathrm{QOOH}$ radical decomposition and the rate of $\mathrm{R}$ and $\mathrm{QOOH} \beta$-scission, thereby lowering significantly the overall rate of reaction.

Thus the first stage ignition in the RCM consists of a period during which the value of the reactant temperature resides within this region of rapid overall reaction rate. Reactant mixtures compressed to temperatures above this region either do not experience the first stage ignition or it occurs briefly during compression as the mixture passes rapidly through this temperature region.

(3) When the compressed gas temperature falls between these extreme values (i.e., $760 \mathrm{~K}<\mathrm{T}_{\mathrm{C}}<900 \mathrm{~K}$ for 8 bar in Fig. 1), then a limited first stage 
ignition occurs, followed by reaction quenching at the temperatures corresponding to minimum reaction rate. When $T_{c}$ lies below the value corresponding to the maximum rate of reaction (i.e., $T_{C}<760 \mathrm{~K}$ for 8 bar in Fig. 1), an extended first stage ignition occurs, again followed by quenching at the lowest reaction rate conditions.

The amount of fuel consumed during this first stage ignition varies, depending on the difference between $T_{C}$ and the temperature $T_{\min }$ corresponding to the lowest overall rate of reaction where the first stage ignition is halted. If this temperature difference $\left(T_{\min }-T_{C}\right)$ is large, then more fuel must be consumed to reach $T_{\text {min }}$ than when $\left(T_{\text {min }}-T_{c}\right)$ is small. There is a subtle trend in $T_{\min }$ found from the computed results that is consistent with the experimental data. Since the amount of fuel consumed during the first stage ignition is larger for large values of $\left(T_{\min }-T_{C}\right)$, the accompanying pressure increase during the first stage ignition is also greater than for smaller values of $\left(T_{\min }-T_{C}\right)$. This difference in pressure shifts the equilibrium in Reactions (2) and (4), producing a small variation in $T_{\min }$ with $T_{C}$. For example, for the stoichiometric mixtures in Fig. $4, T_{\min }=945 \mathrm{~K}$ when $T_{C}=723 \mathrm{~K}$, while $T_{\min }=904 \mathrm{~K}$ when $T_{C}=777 \mathrm{~K}$. 
(4) If appreciable exients of reaction occur during compression, the interpretation of the ignition delay must be modified. In the present work, this situation was observed only at the higher pressures and temperatures examined. In contrast, for the more reactive n-heptane, the first stage of ignition was commonly observed prior to the end of compression $[1,4,27]$. However, even when the first stage begins during compression, it proceeds only until the onset of slow reaction conditions quenches the ignition. Second Stage Ignition

The development of the second stage ignition is driven by the decomposition of hydrogen peroxide. This chemistry governs the part of Fig. 1 at $\mathrm{T} \geq 900 \mathrm{~K}$. If compression has advanced the temperature beyond the region of negative temperature coefficient, then a positive temperature dependence of ignition delay on temperature is observed. If a first stage ignition is observed, then the amount of fuel consumption during the first stage and the temperature attained in the first stage determine the duration of the second stage ignition.

\section{Relationship to Engine Combustion}

Compression ignition in Diesel engines and autoignition leading to knock in spark-ignition engines occur at reactant temperatures in the same range as observed in this study. However, engine pressures at autoignition are commonly in the range of $30-50$ bar, considerably higher than those seen here. The redesign of this RCM to double compression pressures to about 20 . 
bar was in fact motivated in large measure to make the experiments even more relevant to engine autoignition studies. Even so, this RCM has been used [28] to study the behavior of cetane-enhancing additives.

The present family of kinetic reaction mechanisms has been used to study knock chemistry $[21,23,29]$. The excellent agreement between computed and measured results in this RCM provides a valuable test of the mechanism and, by implication, confidence in those engine modeling studies.

An additional interesting insight provided by this experimental and modeling study relates to the concept of fuel octane sensitivity. Fuel octane ratings are determined by comparisons between autoignition of a fuel being tested and two alkane reference fuels, n-heptane and iso-octane. Two different engine cycles are used to define Research and Motored Octane Numbers (RON and MON); octane sensitivity is defined as the difference between RON and MON for a given fuel. Most alkane fuels have low octane sensitivity, while olefin and aromatic hydrocarbons have more pronounced octane sensitivities. The RON and MON tests involve different engine speeds, initial reactant temperatures, and other significant differences in operating parameters, so end gases encounter different temperature histories in the two tests. As the present study of n-pentane autoignition illustrates, the rate of autoignition for alkanes depends in a complex manner on the compressed gas temperature and pressure, due especially to the influence of Reactions 2 and 4 as noted above. The reaction mechanisms of aromatic and olefin fuels do not exhibit such complex behavior, since the roles of alkyl and. 
hydroperoxyalkyl radicals are much less important in their autoignition.

Thus these fuels have high octane sensitivity because their autoignition does not mirror these kinetic complexities, while alkane fuels have low sensitivities because, like n-pentane and the octane reference fuels, they do include the same type of autoignition chemistry as shown in Reactions $1-6$. By defining octane numbers in terms of alkane fuel oxidation, nonlinear and complex reaction paths are built into the rating scale, and non-alkane fuels with inherently simpler oxidation mechanisms appear, erroneously, to be unusual in their ignition properties.

\section{ACKNOWLEDGMENTS}

The authors thank Dr. Nick Marinov for valuable discussions concerning this work. The computational portions of this work were supported by the US Department of Fnergy, Office of Basic Energy Sciences, Division of Chemical Sciences and performed under the auspices of the U.S. Department of Energy by the Lawrence Livermore National Laboratory under contract No. W-7405ENG-48. 
References

1. Griffiths, J.F., Halford-Maw, P.A., and Rose, D.J., Combust. Flame 95, 291 (1993).

2. Minetti, R., Ribaucour, M., Carlier, M., Fittschen, C., and Sochet, L.R., Combust. Flame 96, 201 (1994).

3. Park, P., and Keck, J.C., SAE Paper 900027, 1990.

4. Cox, A., Griffiths, J.F., Mohamed, C., Curran, H.J., Pitz, W.J., and Westbrook, C.K., Twenty-Sixth Symposium (International) on Combustion, The Combustion Institute, Pittsburgh, 1996, p. 2685.

5. Kirsch, L.J., and Quinn, C.P., Sixteenth Symposium (International) on Combustion, The Combustion Institute, Pittsburgh, p. 233 (1976).

6. Carlier, M., Corre, C., Minetti, R., Pauwels, J.-F., Ribaucour, M., and Sochet, L.-R., Twenty-Third Symposium (International) on Combustion, The Combustion Institute, Pittsburgh, p. 1753 (1991).

7. Minetti, R., Carlier, M., Ribaucour, M., Therssen, E., and Sochet, L.-R., Twenty-Sixth Symposium (International) on Combustion, The Combustion Institute, Pittsburgh, p. 747 (1996).

8. Griffiths, J.F., and Scott, S.K., Prog. Energy Combust. Sci. 13, 161 (1987).

9. Griffiths, J.F., and Mohamed, C., Chapter 6 in Comprehensive Chemical Kinetics (G. Hancock, Ed.), Elsevier, Amsterdam, in press (1997).

10. Griffiths, J.F., Prog. Energy Combust. Sci. 21, 25 (1995).

11. Beeley, P., Gray, P., and Griffiths, J.F., Combust. Flame 39, 269 (1980). . 
12. Griffiths, J.F., and Hasko, S.M., Proc. R. Soc. London, Ser. A 393, 371 (1984).

13. Griffiths, J.F., and Perche, A., Eighteenth Symposium (International) on Combustion, The Combustion Institute, Pittsburgh, 1981, p. 893.

14. Griffiths, J.F., Jiao, Q., Schreiber, M., Meyer, J., and Knoche, K.F., Combust. Flame 91, 209 (1992).

15. Lund, C.M., Lawrence Livermore National Laboratory report UCRL$52504,1978$.

16. Griffiths, J.F., Rose, D., Schreiber, M., Meyer, J., and Knoche, K.F., Proc. I. Mech. Eng. C448, 29 (1992).

17. Griffiths, J.F., Jiao, Q., Schreiber, M., Meyer, J., and Knoche, K.F., Twenty-Fourth Symposium (International) on Combustion, The Combustion Institute, Pittsburgh, p. 1809 (1992).

18. Schreiber, M., Sadat-Sakak, A., Poppe, C., Griffiths, J.F., Halford-Maw, P.A., and Rose, D.J., Society of Automotive Engineers paper SAE-932758 (1993).

19. Curran, H.J., Pitz, W.J., Westbrook, C.K., Hisham, M.W.M., and Walker, R.W., Twenty-Sixth Symposium (International) on Combustion, The Combustion Institute, Pittsburgh, 1996, p. 641.

20. Curran, H.J., Gaffuri, P., Pitz, W.J., and Westbrook, C.K., Combust. Flame, in press (1998). 
21. Curran, II.J., Gaffuri, P., Pitz, W.J., Westbrook, C.K., and Leppard, W.R., Twenty-Sixth Symposium (International) on Combustion, The Combustion Institute, Pittsburgh, 1996, p. 2669.

22. Curran, H.J., Pitz, W.J., Westbrook, C.K., Callahan, C.V., and Dryer, F.L., submitted for publication, 1997.

23. Westbrook, C.K., Pitz, W.J., and Leppard, W.R., Society of Automotive Engineers paper SAE-912314 (1991).

24. Pollard, R.T., Comprehensive Chemical Kinetics, (C.H. Bamford and C.F.H. Tipper, Eds.), Elsevier, New York, Vol. 17, p. 249, 1977.

25. Low Temperature Oxidation and Ignition of Hydrocarbons, Comprehensive Chemical Kinetics, (Hancock, G., Ed.), Elsevier, New York, in press, 1997.

26. Dagaut, P., Reuillon, M., and Cathonnet, M., Comb. Sci. Tech. 95, 233 (1994).

27. Griffiths, J.F., Halford-Maw, P., and Mohamed, C., Combust. Flame 111, 327 (1997).

28. Inomata, T., Griffiths, J.F., and Pappin, A.J., Twenty-third Symposium (International) on Combustion, The Combustion Institute, Pittsburgh, p. 1759 (1991).

29. Curran, H.J., Gaffuri, P., Pitz, W.J., Westbrook, C.K., and Leppard, W.R., Society of Automotive Engineers publication SAE-952406 (1995). 


\section{FIGURE CAPTIONS}

1. Computed isothermal rate of fuel consumption at selected temperatures. Symbols indicate computed results, curves are fits to those points.

2. Experimental pressure records for ignition following compression to $765( \pm 5 \mathrm{~K})$ at indicated values of equivalence ratio. Inital pressures are all 0.33 bar.

3. Experimental pressure records for ignition following compression to $724( \pm 6 \mathrm{~K})$ at indicated values of equivalence ratio. Inital pressures are all 0.33 bar.

4. Variations in total ignition delay time with compression temperature for selected values of equivalence ratio. Curves represent fits to experimental results, symbols indicate computed results. Inital pressures are all 0.33 bar.

5. Experimental pressure records for stoichiometric n-pentane mixtures with adiabatic compression temperatures of $835 \mathrm{~K}$, at initial precompression pressures of $0.33,0.5$ and 0.67 bar. Also shown as dashed curves are measured light output showing onset of first stage of ignition.

6. Experimentally measured total ignition delay times with adiabatic compression temperature for stoichiometric mixtures at indicated initial pressures. The curves are smooth fits to the experimental data points. 


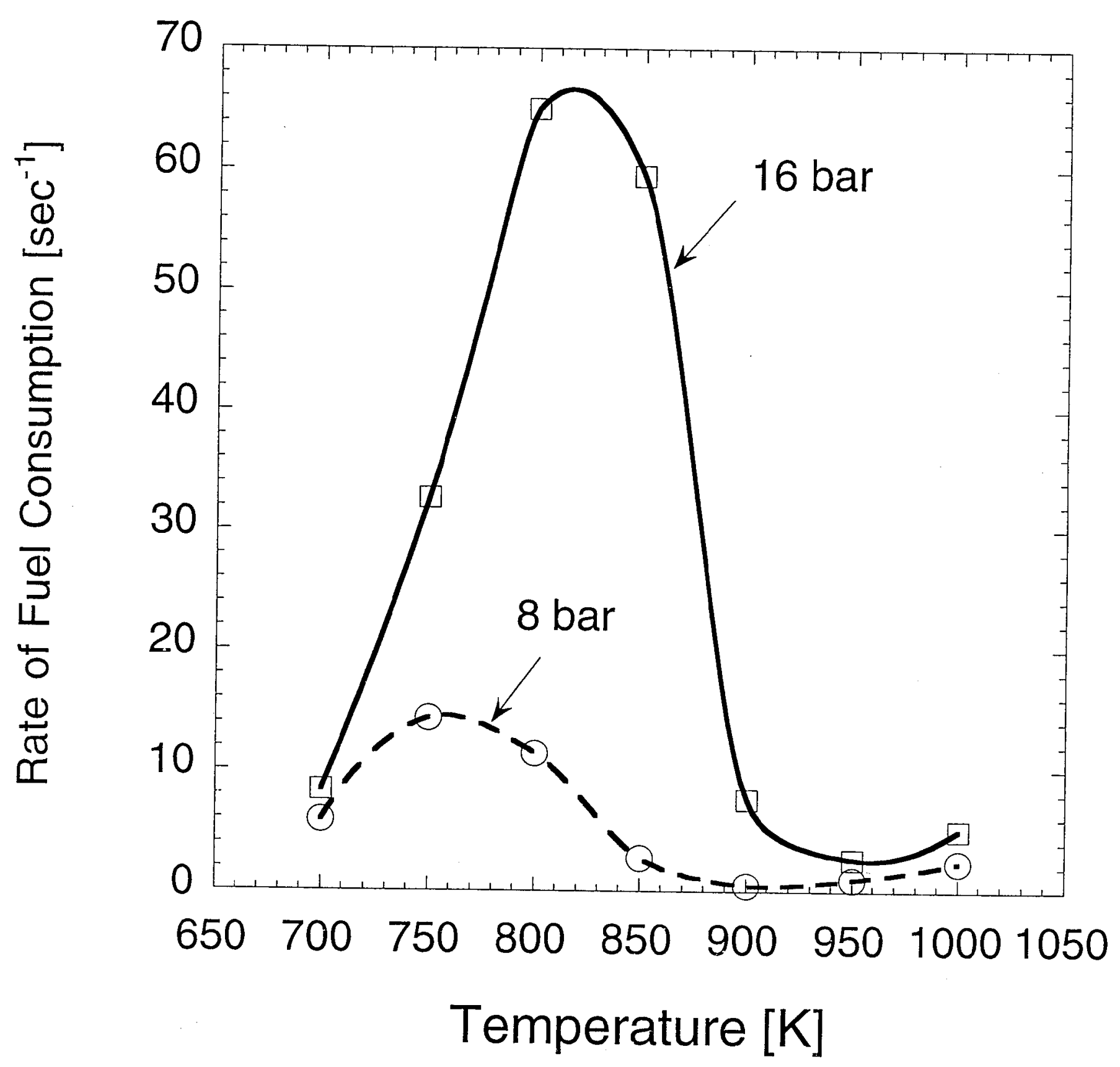

Fig 1 


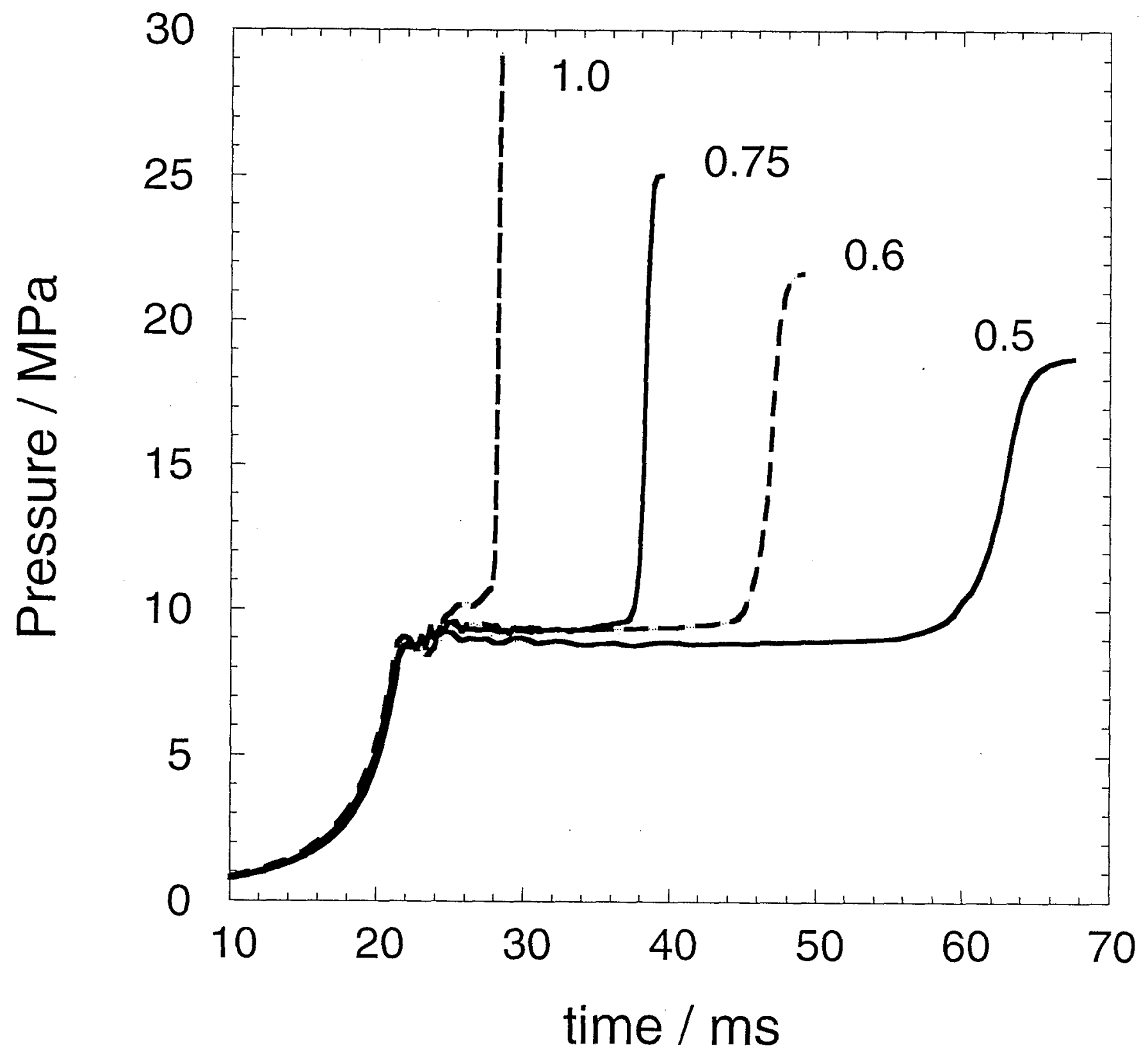

Fig. 2 


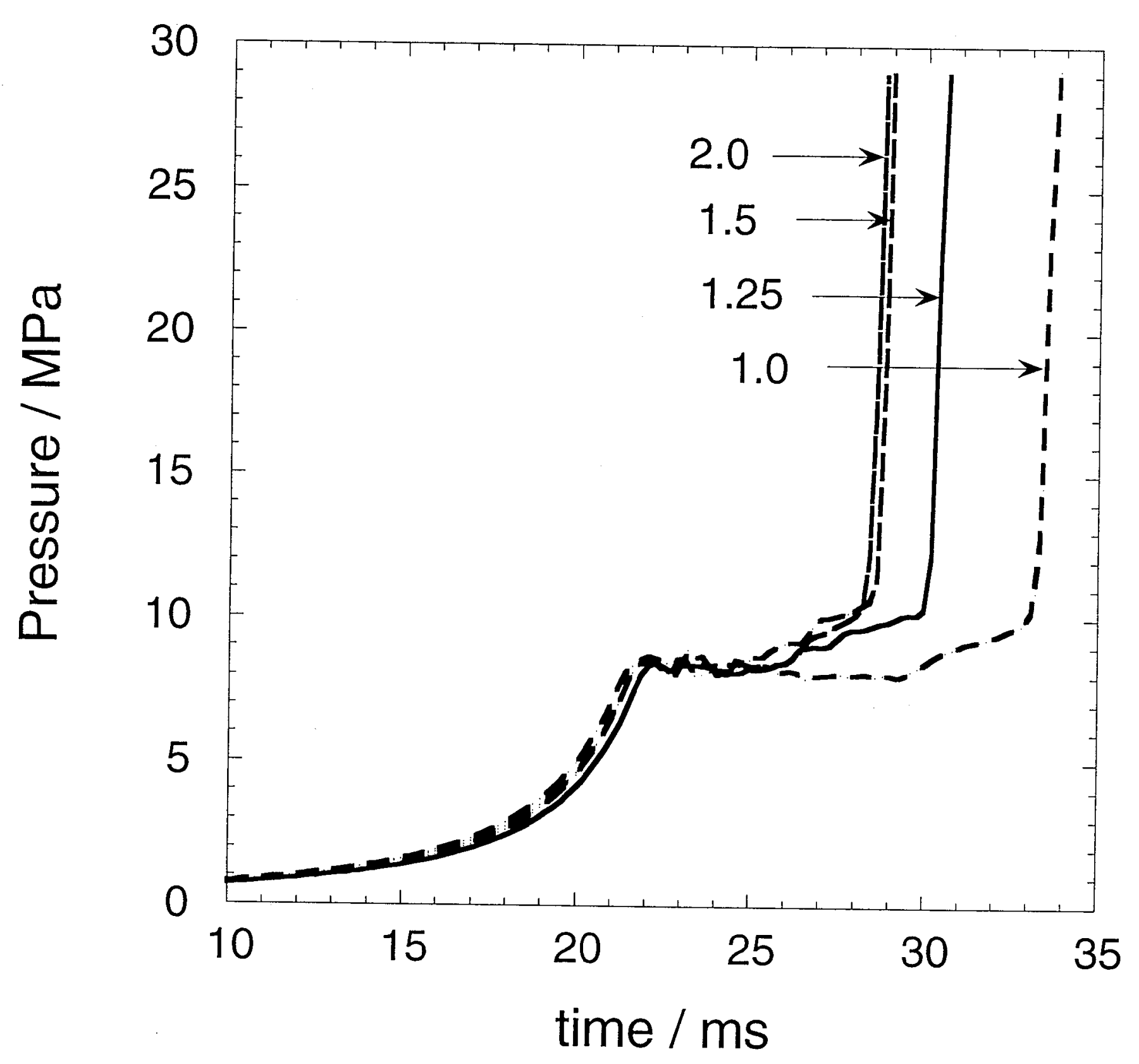

$F$ ig. 3 


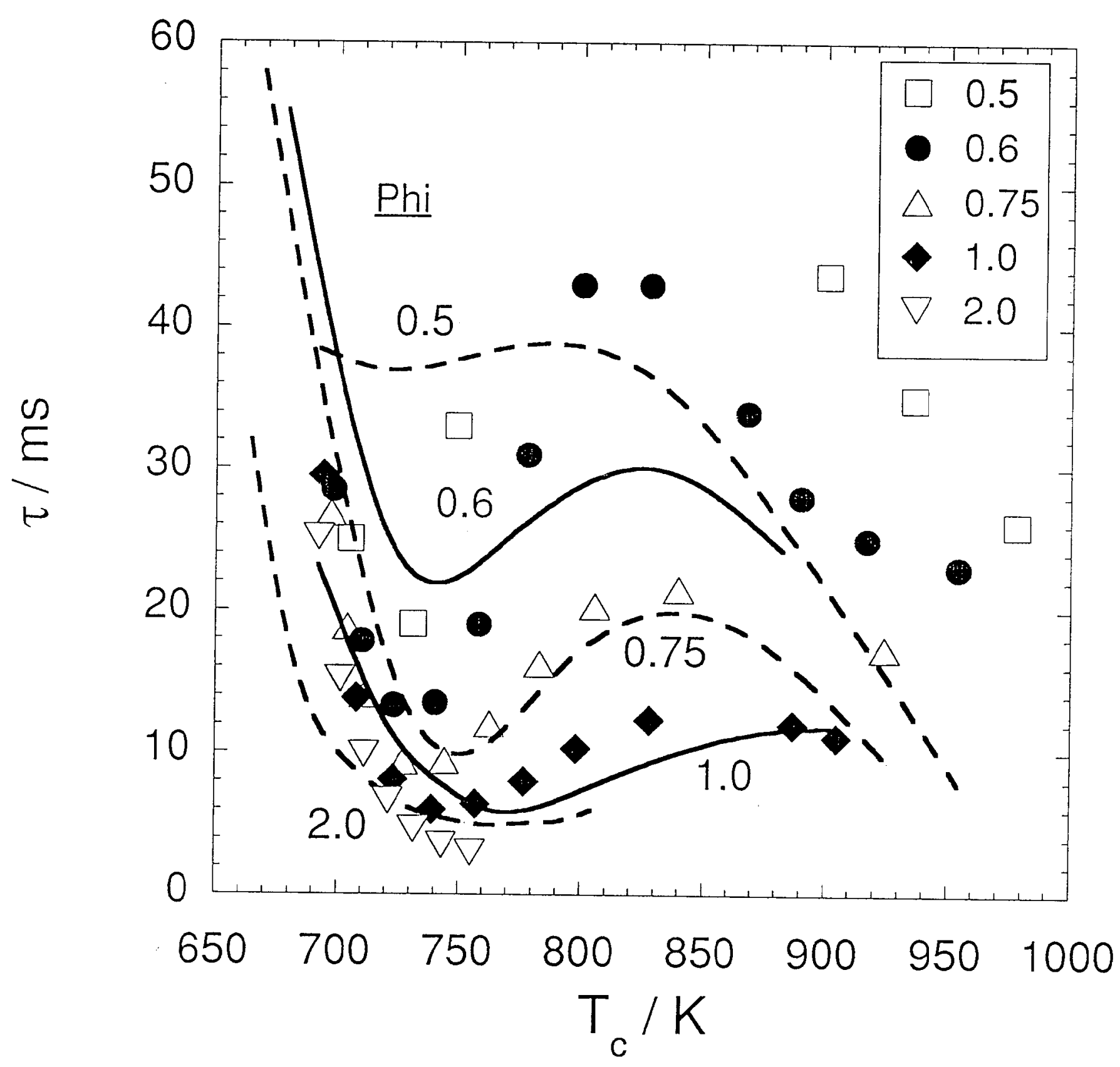

Fig. 


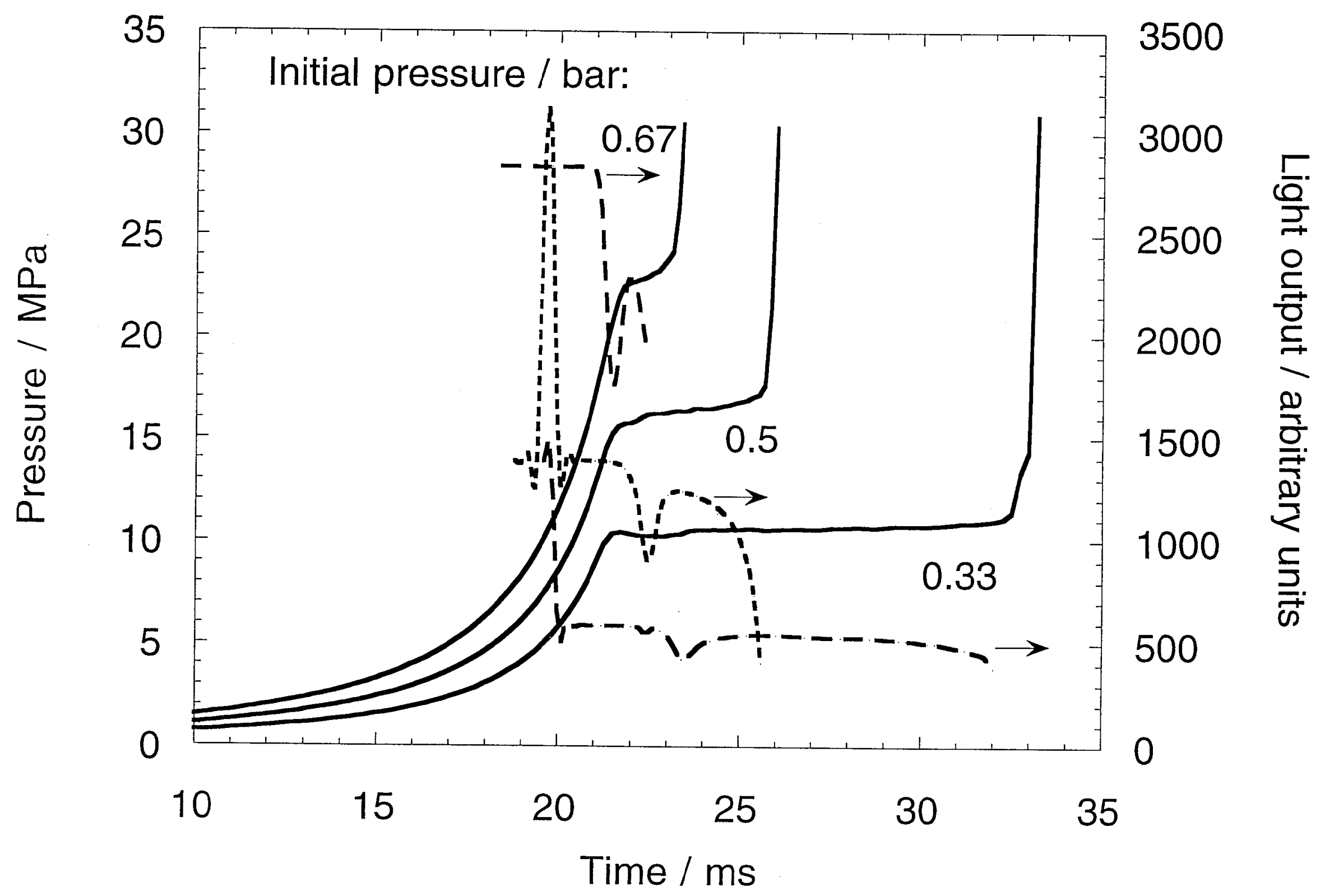




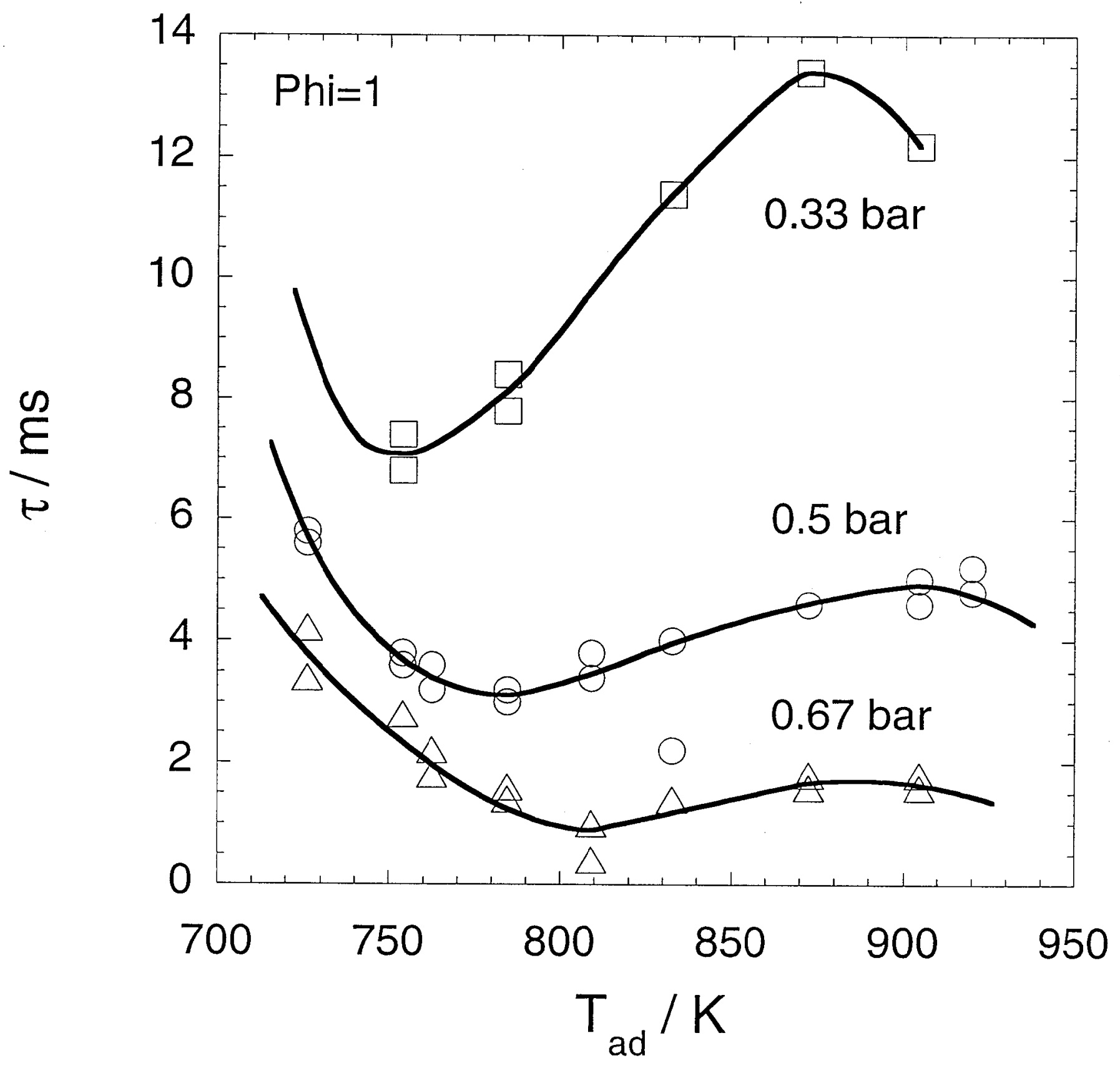

